Prepared for the U.S. Department of Energy

under Contract DE-AC05-76RL01830

\title{
Multiple Lines of Evidence
}

\section{BG Amidan}

A Venzin

L Bramer

August 2015

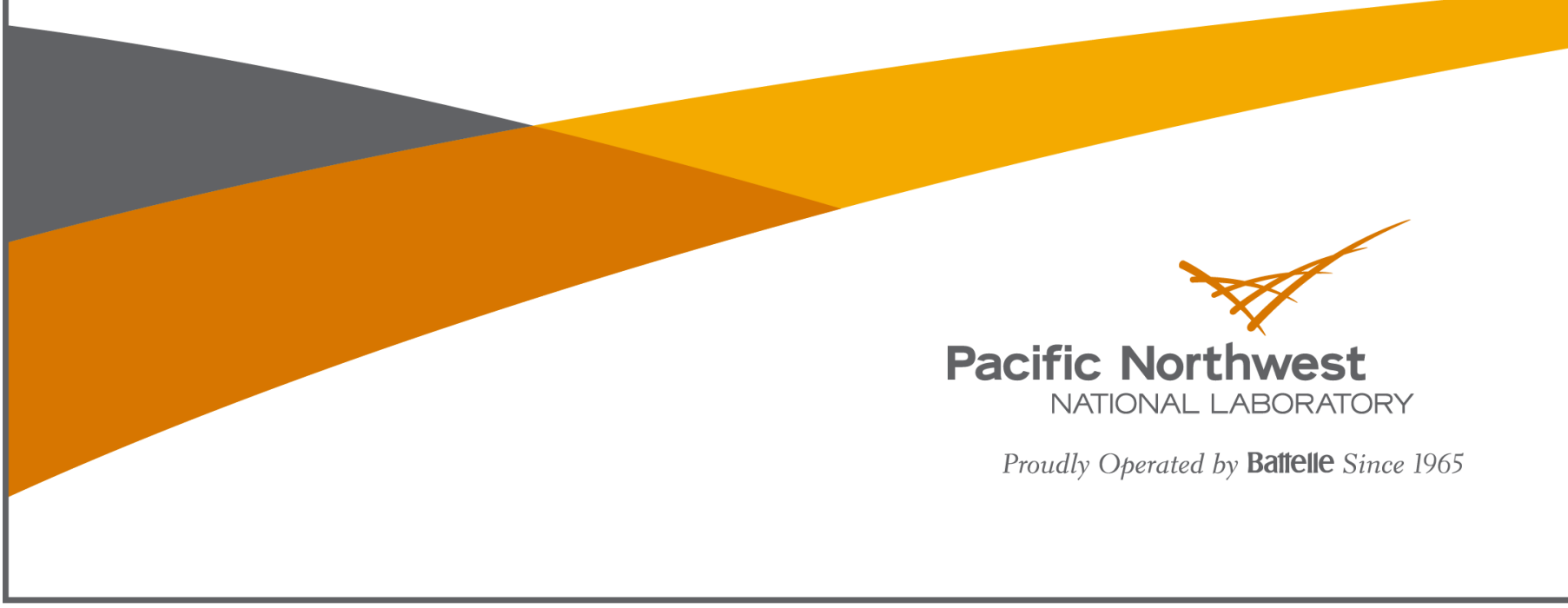




\title{
DISCLAIMER
}

This report was prepared as an account of work sponsored by an agency of the United States Government. Neither the United States Government nor any agency thereof, nor Battelle Memorial Institute, nor any of their employees, makes any warranty, express or implied, or assumes any legal liability or responsibility for the accuracy, completeness, or usefulness of any information, apparatus, product, or process disclosed, or represents that its use would not infringe privately owned rights. Reference herein to any specific commercial product, process, or service by trade name, trademark, manufacturer, or otherwise does not necessarily constitute or imply its endorsement, recommendation, or favoring by the United States Government or any agency thereof, or Battelle Memorial Institute. The views and opinions of authors expressed herein do not necessarily state or reflect those of the United States Government or any agency thereof.

\author{
PACIFIC NORTHWEST NATIONAL LABORATORY \\ operated by \\ BATTELLE \\ for the \\ UNITED STATES DEPARTMENT OF ENERGY \\ under Contract DE-AC05-76RL01830
}

Printed in the United States of America
Available to DOE and DOE contractors from the Office of Scientific and Technical Information,
P.O. Box 62, Oak Ridge, TN 37831-0062;
ph: (865) 576-8401
fax: $(865) 576-5728$
email: reports@adonis.osti.gov
Available to the public from the National Technical Information Service
5301 Shawnee Rd., Alexandria, VA 22312
ph: (800) 553-NTIS (6847)
email: $\underline{\text { orders} @ n t i s . g o v}<$ http://www.ntis.gov/about/form.aspx >
Online ordering: http://www.ntis.gov

This document was printed on recycled paper. 
PNNL-24245

\section{Multiple Lines of Evidence}

BG Amidan

A Venzin
L Bramer

August 2015

Prepared for the U.S. Department of Homeland Security Science and Technology Directorate and the U.S. Department of Energy under Contract DE-AC05-76RL01830

Pacific Northwest National Laboratory

Richland, Washington 99352 



\section{Acknowledgments}

The Pacific Northwest National Laboratory (PNNL) work was funded by the Chemical and Biological Research and Development Branch of the Chemical and Biological Division in the Science and Technology Directorate of the Department of Homeland Security (DHS). The financial support and guidance for this work by Randy Long (DHS) is greatly appreciated. The input and support provided by members of the Validated Sampling Plan Working Group (VSPWG) are also acknowledged. The intraagency VSPWG includes representatives from DHS, the Environmental Protection Agency (EPA), and the Centers for Disease Control and Prevention (CDC). PNNL is a multi-program national laboratory operated for the U.S. Department of Energy by Battelle under Contract DE-AC05-76RL01830.

The authors acknowledge and thank PNNL staff member Brent Daniel for providing a technical review. 



\section{Executive Summary}

This paper discusses the process of identifying factors that influence the contamination level of a given decision area and then determining the likelihood that the area remains unacceptable. This process is referred to as "lines of evidence". These "lines of evidence" then serve as inputs for the stratified compliance sampling (SCS) method, which requires a decision area to be divided into strata based upon contamination expectations. This is done in order to focus sampling efforts more within stratum where contamination is more likely and to use the domain knowledge about these likelihoods of the stratum remaining unacceptable to "buy" down the number of samples necessary, if possible. Two different building scenarios were considered as an example (see Table 3.1). SME expertise was elicited concerning four lines of evidence factors (see Table 3.2) - 1) amount of contamination that was seen before decontamination, 2) post-decontamination air sampling information, 3) the applied decontaminant information, and 4) the surface material. Statistical experimental design and logistic regression modelling were used to help determine the likelihood that example stratum remained unacceptable for a given example scenario.

The number of samples necessary for clearance was calculated by applying the SCS method to the example scenario, using the estimated likelihood of each stratum remaining unacceptable as was determined using the lines of evidence approach. The commonly used simple random sampling (SRS) method was also used to calculate the number of samples necessary for clearance for comparison purposes. The lines of evidence with SCS approach resulted in a 19\% to $43 \%$ reduction in total number of samples necessary for clearance (see Table 3.6). The reduction depended upon the building scenario, as well as the level of percent clean criteria. A sensitivity analysis was also performed showing how changing the estimated likelihoods of stratum remaining unacceptable affect the number of samples necessary. In conclusion, using the lines of evidence approach with the SCS method can reduce sample sizes when SME are able to identify factors that reduce the likelihood that an area remain unacceptable. 


\section{Contents}

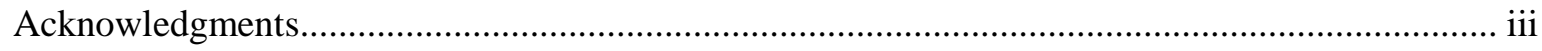

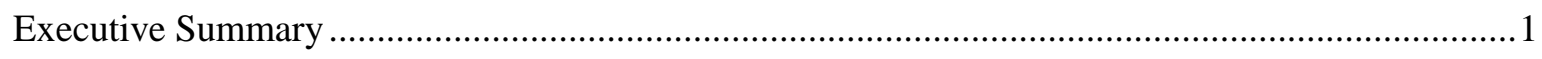

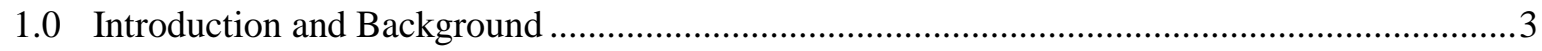

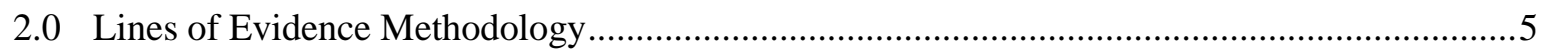

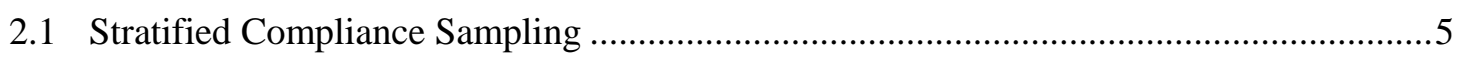

2.2 Elicit Lines of Evidence from Subject Matter Experts........................................................5

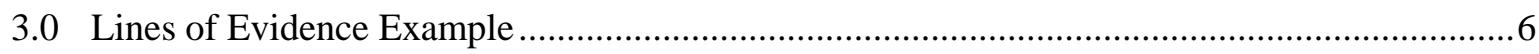

3.1 Example Elicitation from Subject Matter Experts .......................................................6

3.2 Converting SME Expertise to Stratified Compliance Sampling Inputs ........................... 7

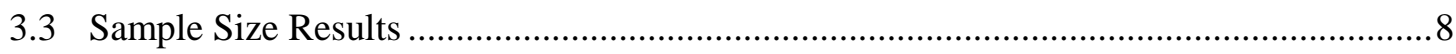

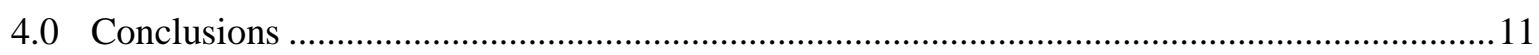

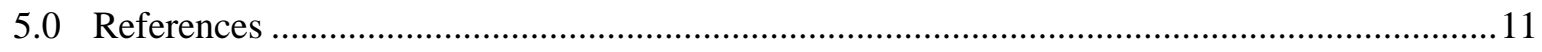




\subsection{Introduction and Background}

A Government Accountability Office (GAO) investigation following the 2001 anthrax incident concluded that validated sampling methods and statistical sampling plans were needed to provide confidence that there is no contamination when all sample results are negative (GAO, 2005). This conclusion strongly reinforces the need for characterized, validated sampling plans to effectively respond to bio-threats and ensure public safety. In addition, surface sampling is critical in two phases of recovery from a biological contamination incident:

- Locating contamination during the characterization phase, and

- Verifying areas are uncontaminated or sufficiently decontaminated during the clearance phase of the restoration process.

Sampling plans are an essential element when characterization or clearance is required for a contaminated or possibly contaminated area (referred to as the decision area). Sampling plans rely upon statistical sampling techniques to determine the necessary number of samples and the amount of confidence that can be obtained when clearing the decision area. Generally, sampling plans that make no assumptions about the contamination or the decontaminant will require many probabilistic (simple random) samples to be taken, in order to obtain a high amount of confidence that a high amount of the decision area is clean (no contaminant found). When characteristics about the contamination and/or decontaminant are understood, then assumptions can be made and statistical methodologies can be produced which will use those assumptions to drive down the number of samples needed for clearance of a decision area. The combined judgmental and random (CJR) method (Sego et al. 2007, 2010) and stratified compliance sampling (SCS) method (Venzin and Sego 2015) were derived to do just that.

The CJR method requires that the decision area be divided into high-risk and low-risk areas. The high-risk area is fully sampled and these samples are called judgmental samples while the low-risk area is randomly sampled at a smaller rate. Two additional parameters concerning the high-risk area samples are needed. These parameters are 1) $P_{J}$, the likelihood of the high-risk area samples being acceptable (no detectable contaminant); and 2) $r$, the likelihood ratio between the high-risk area samples being unacceptable compared to the low-risk area samples. As $P_{J}$ and $r$ increase, less samples will be necessary.

The stratified compliance sampling (SCS) method extends the CJR method to an arbitrary number of risk based areas. The assumption remains that subject matter experts are capable of identifying an area that is most likely to harbor unacceptable samples (detectable contaminant). Knowledge obtained from sampling items in this highest-risk area affect the likelihood of finding an unacceptable item elsewhere in the decision area. Furthermore, instead of a single value of $r$, the model assumes that a set of $r$ values can be determined that augments the acceptability of items within each stratum. As in the CJR model, judicious choices of $\mathrm{P}_{J}$ and the set of $r$ values can significantly reduce the sample size required to meet a target confidence.

The information that is needed for the CJR or SCS methods to define the high-risk areas and to understand the characteristics of the high-risk areas is not always available or well understood. This makes applying these methods difficult, because of the uncertainty in these pieces of information. Also, these methods do not allow for other types of information to influence sample size. It was decided to 
develop a methodology that would help map these other pieces of information to the likelihood based inputs needed for the stratified sampling method. This method is called "lines of evidence".

The lines of evidence approach for determining the number of samples necessary to clear a decontaminated area is dependent on understanding many other factors about the scenario of interest. Two of these possible factors could be the amount of contamination present and the effectiveness of the selected decontamination method. The amount of contamination can be estimated if information is available about the contamination release (where, how, how much, etc.) and/or samples are taken to quantify the amount of contamination. Models can be applied to this information to give an estimate of the contamination across the whole area of interest. Possible models could be produced using software like CONTAM (Walton and Dols 2013) or statistically-based algorithms like kriging.

Decontamination effectiveness can be estimated by knowing which decontamination method is selected and knowing under what conditions the decontamination method is being used. Different decontamination methods and conditions have been studied and summarized in the literature (some examples include U.S. EPA 2010 and Ryan et al. 2010). Decontamination methods were generally tested in an attempt to demonstrate at least a $6 \log _{10}$ deduction (Ryan et al 2010). This was done because a $6 \log _{10}$ deduction was being considered as a requirement for product registration as a sporicidal agent against spores of Bacillus anthracis Ames" (U.S. EPA 2007).

Many factors can influence decontamination efficacy. These factors have to do with the decision area environment, the contaminant, and the decontaminant. Environmental factors include: temperature, relative humidity, sunlight, type of material the contaminant is on, and the amount of background bioburden in the contaminated area. The contaminant factors include: the actual contaminant used, the method of preparation for the contaminant, the contaminant deposition method, and the amount of contaminant applied. The decontaminant factors include: the amount of decontaminant applied, and the decontaminant exposure contact time. There are likely many other factors that could be considered in each of these categories. Decontamination studies (U.S. EPA 2010 and Ryan et al. 2010) made the following observations -

- the contaminant is more persistent at lower temperatures;

- relative humidity has a varying effect on the contaminant;

- the contaminant is most persistent in aqueous environments, less stable on fomites, and least persistent as an aerosol; and

- the use of B. subtilis had a lower efficacy when compared to B. anthracis.

Other factors may be considered as lines of evidence. This may include air sampling results after decontamination and the surfaces within the decision area. Subject matter experts (SME) may discover other factors which provide further evidence into the clearance of a decontaminated area. All of these factors can provide evidence of a successful decontamination and can help determine the likelihood that an area is still unacceptable (contaminated). This paper will demonstrate how relying on SME expertise to estimate the effect of non-surface sampling factors for a given scenario can be used in conjunction with the SCS method to reduce the number of surface samples that will be needed to achieve a given confidence level. 


\subsection{Lines of Evidence Methodology}

The "lines of evidence" methodology relies on the stratified compliance sampling approach to help reduce numbers of samples needed to clear a contaminated area with confidence. This section discusses how to elicit the probabilities from domain experts that are needed for stratified compliance sampling.

\subsection{Stratified Compliance Sampling}

The stratified compliance sampling methodology requires that the full decision area be divided up into various strata based upon factors like likelihood that contamination exists, difficulty to decontaminate, surface material, etc. Each stratum will then result in an area that is homogenous. After the strata are defined, the investigator must determine the a priori probability that an unacceptable item exists for each stratum. The investigator is also asked to provide a set of "relative risk" terms determining the ratio of the unacceptability of items in the stratum with the largest a priori probability to all of the other strata. These strata definitions and the associated risks, as well as the desired confidence level and minimum proportion of acceptability (i.e. $95 \%$ confident that at least $95 \%$ of the decision area is acceptable) make up the inputs for the SCS model. Details concerning the SCS methodology can be found in (Venzin and Sego, 2015).

It is important to note that defining strata and the risk associated with each stratum is subjective and prone to error. However, careful and conservative accounting for these quantities will improve the sampling plan by requiring fewer samples than would be expected from traditional approaches.

\subsection{Elicit Lines of Evidence from Subject Matter Experts}

Considering lines of evidence factors can help the SME determine better stratum and better estimates of the risk. For example, if a stratum was very lightly contaminated on a surface that is easy to clean and a decontamination method was applied that is well known to clean the contaminated area, then the resulting input to the SCS model should indicate a very low probability that the stratum is still unacceptable. Likewise, if a stratum was heavily contaminated and the air sampler detects contamination after the decontamination, the probability that the stratum is still unacceptable should be very high.

The lines of evidence methodology relies upon the SME to determine these values of probability that a stratum is still unacceptable. The SME should consider all possible evidence to do this and may choose to give a conservative estimate. In Section 3, an example is shown that takes the domain experts opinions concerning four possible evidence factors and uses a regression model to help apply that to example stratum. The SCS approach is then employed and the reduction in numbers of samples necessary for clearance is shown. 


\subsection{Lines of Evidence Example}

This section describes how the lines of evidence methodology could be applied to two different building scenarios. These building scenarios are summarized in Table 3.1.

Table 3.1. Lines of Evidence Building Scenario Examples

\begin{tabular}{||c|c|c|c|c|c||}
\hline \hline Scenario & $\begin{array}{c}\text { Total } \\
\text { Square Footage }\end{array}$ & $\begin{array}{c}\text { Carpet } \\
\text { Square Footage }\end{array}$ & $\begin{array}{c}\text { Vinyl } \\
\text { Square Footage }\end{array}$ & $\begin{array}{c}\text { Drywall } \\
\text { Square Footage }\end{array}$ & $\begin{array}{c}\text { Stainless Steel } \\
\text { Square Footage }\end{array}$ \\
\hline \hline 1 & 5000 & 500 & 2000 & 1000 & 1500 \\
\hline 2 & 4000 & 1000 & 1000 & 1000 & 1000 \\
\hline
\end{tabular}

Section 3.1 discusses what factors are considered as lines of evidence for this example and how SME expertise is collected. Section 3.2 discusses how the SME expertise can be translated into the inputs needed for the stratified sampling approach. Section 3.3 shows the necessary sample size results when applying these methods to the two building scenarios.

\subsection{Example Elicitation from Subject Matter Experts}

For this example, four factors were considered to demonstrate the lines of evidence approach. These four factors and the possible levels of these factors are summarized in Table 3.2.

Table 3.2. Lines of Evidence Factors Considered for this Example

\begin{tabular}{||c|c||}
\hline \multicolumn{1}{|c|}{ Factor } & \multicolumn{1}{c|}{ Possible Levels } \\
\hline \hline \multirow{2}{*}{ Amount of Contamination (pre-decon) } & 1) Area was highly contaminated \\
& 2) Area was lightly contaminated \\
\hline \multirow{2}{*}{ Air Sampling (post-decon) Information } & 1) Small amount of contamination detected \\
& 2) No contamination was detected \\
\hline \multirow{2}{*}{ General Decon Method Information } & 1) Method has consistently shown a 6 log kill \\
& 2) Method has NOT consistently shown a 6 log kill \\
\hline \multirow{2}{*}{ Surface Material } & 1) Carpet \\
& 2) Vinyl \\
& 3) Stainless Steel \\
& 4) Drywall \\
\hline \hline
\end{tabular}

These four factors resulted in 32 possible different combinations $(2 \times 2 \times 2 \times 4)$. Using experimental design principles, it is possible to get a measure for these 32 combinations by only sampling a specific set of 16 of them. In this case a half-replication fractional factorial design is followed to determine which 16 scenarios should be considered (Dean \& Voss, 1999). An SME was asked to estimate the probability that an area was still unacceptable, for each of the 16 certain contamination scenarios involving these four factors. The results of these estimates are found in Table 3.3. 
In this case a half-replication fractional factorial design is used to elicit a few estimations of these probabilities of an area being unacceptable from SME. A quarter-replication or even an eighthreplication could be used depending on the situation. These fractional designs allow a few estimations of these probabilities to be used to infer probabilities for any combination of these factors.

Table 3.3. Estimated Probability of an Area Still Being Unacceptable (Contaminated) Given a Specific Contamination Scenario

\begin{tabular}{|c|c|c|c|c|}
\hline $\begin{array}{c}\text { Amount of Contamination } \\
{\text { (Pre-Decon) })^{\mathrm{a}}}^{\text {(Pre }}\end{array}$ & $\begin{array}{l}\text { Air Sampling (Post- } \\
\text { Decon) Information }\end{array}$ & $\begin{array}{c}\text { General Decon } \\
\text { Method Information }\end{array}$ & $\begin{array}{c}\text { Surface } \\
\text { Material }\end{array}$ & $\begin{array}{l}\text { SME Probability of Area } \\
\text { Being Unacceptable }^{\mathrm{d}}\end{array}$ \\
\hline High & "High & High & Carpet & 0.999 \\
\hline High & Low & Low & Carpet & 0.20 \\
\hline Low & Low & High & Carpet & 0.25 \\
\hline Low & High & Low & Carpet & 0.999 \\
\hline High & Low & High & Vinyl & 0.15 \\
\hline High & High & Low & Vinyl & 0.999 \\
\hline Low & High & High & Vinyl & 0.999 \\
\hline Low & Low & Low & Vinyl & 0.05 \\
\hline High & High & High & St Steel & 0.999 \\
\hline High & Low & Low & St Steel & 0.05 \\
\hline Low & Low & High & St Steel & 0.15 \\
\hline Low & High & Low & St Steel & 0.999 \\
\hline High & Low & High & Drywall & 0.15 \\
\hline High & High & Low & Drywall & 0.999 \\
\hline Low & High & High & Drywall & 0.999 \\
\hline Low & Low & Low & Drywall & 0.05 \\
\hline
\end{tabular}

a High = Area was highly contaminated pre-decon; Low = area was lightly contaminated pre-decon

$\mathrm{b}$ High $=$ Small amount of contamination detected; Low $=$ No contamination was detected

$\mathrm{c}$ High $=$ Method has consistently shown a $6 \log$ kill rate in the lab; Low = Method hasn't consistently shown a 6 log kill rate in the lab d SME's estimates of the probability of an area still being unacceptable (contaminated)

\subsection{Converting SME Expertise to Stratified Compliance Sampling Inputs}

The 16 scenarios and probability estimates, as shown in Table 3.3, are then used to fit a logistic regression equation. This equation has the following form:

$$
f(x)=b_{0}+b_{1} x_{1}+b_{2} x_{2}+b_{3} x_{3}+b_{4} x_{4}
$$

where $b_{0}$ is the intercept, $x_{1}$ is the amount of contamination ( $1=$ high, $0=$ low $), x_{2}$ is the air sampling information ( $1=$ high, $0=$ low), $x_{3}$ is the decontamination information ( $1=$ high, $0=$ low $), x_{4}$ is the surface material ( $1=$ carpet, $0=$ others), and $b_{1}$ through $b_{4}$ are the slopes associated with $x_{1}$ through $x_{4}$. To calculate the estimated probability of a given stratum still being unacceptable, Equation 3.1 is used with the logistic function:

$$
p(x)=\frac{e^{f(x)}}{e^{f(x)}+1}=\frac{1}{1+e^{-f(x)}}
$$


where $f(x)$ is defined in Equation 3.1.

Table 3.4 contains the coefficients for the intercept and slopes when fitting the equation from the data in Table 3.3. Using these coefficients, values for the factors (the $x$ 's) for a given scenario, and equations 3.1 and 3.2, estimates for a given stratum being unacceptable can be calculated. For this example, it was decided to consider the scenario that the decision area was highly contaminated before decon, the air sampler detected no contamination after decon, and the decon technology had consistently demonstrated a better than $6 \log$ kill rate. The area was divided into four strata, based on the surface material. These materials were carpet, vinyl, stainless steel, and drywall. Table 3.5 shows the estimated probability of the area still being unacceptable for each of these strata using the coefficients in Table 3.4. This scenario was considered for each of the two different building scenarios that are explained in Table 3.1.

The estimated probabilities of each strata being unacceptable found in Table 3.5 are inputs for the SCS method. The SCS method requires two inputs from the lines of evidence approach:

- $\theta$, the probability that a grid cell in the highest risk stratum is unacceptable

- $\rho_{i}$, the pre-existing belief of the unacceptability of a grid cell in stratum $i$ relative to the highest risk stratum.

Section 3.3 discusses how the results from this example are used to calculate the number of samples needed when using the SCS method for each of the two different building scenarios explained in Table 3.1.

Table 3.4. Logistic Regression Coefficients

\begin{tabular}{||c|c|c|c|c|}
\hline $\mathbf{b}_{\mathbf{0}}$ & $\mathbf{b}_{\mathbf{1}}$ & $\mathbf{b}_{\mathbf{2}}$ & $\mathbf{b}_{\mathbf{3}}$ & $\mathbf{b}_{\mathbf{4}}$ \\
\hline \hline-2.874 & 0.289 & 9.116 & 0.870 & 1.031 \\
\hline
\end{tabular}

Table 3.5. Estimated Probability of an Area Being Unacceptable for Four Selected Strata

\begin{tabular}{||c|l|c|c|c||}
\hline \multirow{2}{*}{ Strata } & \multicolumn{1}{|c|}{ Conditions } & $\begin{array}{c}\text { Surface } \\
\text { Material }\end{array}$ & $\begin{array}{c}\text { Estimated Probability of } \\
\text { Area Being Unacceptable }\end{array}$ & $\boldsymbol{\rho}_{\boldsymbol{i}}$ \\
\hline \hline 1 & \multirow{2}{*}{$\begin{array}{l}\text { Area was highly contaminated (pre- } \\
\text { decon); No contamination detected by } \\
\text { air sampling (post-decon); Decon } \\
\text { method has consistently demonstrated a }\end{array}$} & Carpet & $0.174(\theta)$ & 1 \\
\cline { 3 - 5 } & \begin{tabular}{l} 
Vinyl \\
\cline { 3 - 5 }
\end{tabular} & St Steel & 0.070 & 0.4023 \\
\cline { 3 - 5 } & Drywall & 0.070 & 0.4023 \\
\hline 4 & & 0.070 & 0.4023 \\
\hline
\end{tabular}

\subsection{Sample Size Results}

The lines of evidence outputs from Table 3.5 are converted to the inputs for the SCS method. For this example, $\theta$ is 0.174 , which is the probability that a grid cell in the highest risk stratum (Strata 1 ) is 
unacceptable. $\rho_{i}$ is the ratio of a grid cell being unacceptable for strata $i$ relative to the highest risk stratum. The last column in Table 3.5 lists the $\rho$ values.

Using 95\% confidence and the $\theta$ and $\rho_{i}$ values from Table 3.5, the SCS methodology was applied to each building scenario to calculate how many samples would be needed. Table 3.6 shows the numbers of samples needed for each stratum for each building scenario when considering $95 \%$ confidence that at least $95 \%$ of the area is clean and $95 \%$ confidence that at least $99 \%$ of the area is clean. This was done for both stratified compliance sampling and acceptance sampling from a hypergeometric distribution (Sego et al 2007, 2010). This form of acceptance sampling can be thought of as "simple random sampling" assuming an underlying hypergeometric distribution. The SCS methodology resulted in a sample size reduction of between $19 \%$ (building scenario 2 with $99 \%$ clean) and $43 \%$ (building scenario 1 with $95 \%$ clean) relative to simple random sampling. In each case, this is a significant reduction in the number of samples needed for clearance, although it is important to note that results will vary according to each situation and the estimates for $\theta$ and $\rho_{i}$.

Table 3.6. Total Number of Samples Necessary for Simple Random and Stratified Compliance Sampling for Each Scenario

\begin{tabular}{|c|c|c|c|c|c|c|c|c|}
\hline \multirow[b]{3}{*}{ Strata } & \multicolumn{4}{|c|}{ Building Scenario 1} & \multicolumn{4}{|c|}{ Building Scenario 2} \\
\hline & \multicolumn{2}{|c|}{$\begin{array}{c}\text { Simple Random } \\
\text { Sample }\end{array}$} & \multicolumn{2}{|c|}{$\begin{array}{c}\text { Stratified Compliance } \\
\text { Sample }\end{array}$} & \multicolumn{2}{|c|}{$\begin{array}{c}\text { Simple Random } \\
\text { Sample }\end{array}$} & \multicolumn{2}{|c|}{$\begin{array}{c}\text { Stratified Compliance } \\
\text { Sample }\end{array}$} \\
\hline & $95 \%^{\mathrm{a}}$ & $99 \%^{\mathrm{a}}$ & $95 \%^{a}$ & $99 \%{ }^{\mathrm{a}}$ & $95 \%^{\mathrm{a}}$ & $99 \%^{\mathrm{a}}$ & $95 \%^{\mathrm{a}}$ & $99 \%^{a}$ \\
\hline 1 & 10 & 29 & 15 & 84 & 15 & 70 & 18 & 100 \\
\hline 2 & 19 & 114 & 6 & 37 & 15 & 70 & 8 & 42 \\
\hline 3 & 13 & 57 & 6 & 35 & 15 & 70 & 8 & 42 \\
\hline 4 & 16 & 85 & 6 & 36 & 15 & 70 & 8 & 42 \\
\hline Total & 58 & 285 & 33 & 192 & 60 & 280 & 42 & 226 \\
\hline
\end{tabular}

a The percentage of area to be expected to be clean, given $95 \%$ confidence.

The estimated probability that a grid cell in the highest risk stratum is unacceptable $(\theta)$ and the estimated ratios of a grid cell being unacceptable for each stratum to the highest risk stratum $\left(\rho_{i}\right)$ are inputs into the SCS method and each influence the calculated number of samples. A sensitivity analysis was performed to look at the effect that changing these inputs has on the number of samples necessary for clearance. Figure 3.1 shows how the required total number of samples changes as both the SME prior $(\theta)$ and the $\rho$ values change, for each of the building scenarios and the $95 \%$ and $99 \%$ clean criteria. The three lines on each plot represent the SME value for $\theta(0.174)$, a $20 \%$ decrease in $\theta(0.139)$, and a $40 \%$ decrease in $\theta(0.1044)$. The x-axis represents the $\rho$ values for strata $2-4$. The $\rho$ values at the SME point are (1, $0.4023,0.4023,0.4023)$ for the four strata. Each value to the right of that is a reduction in the $\rho$ values for strata $2-4$. For example, the " $-20 \%$ " point represents the $\rho$ values $(1,0.3218,0.3218,0.3218)$, while the " $-60 \%$ " point represents the $\rho$ values $(1,0.1609,0.1609,0.1609)$. From this plot it is evident that the changes in $\rho$ values have a greater impact on the required number of samples than the changes in $\theta$, especially when considering at least $99 \%$ clean as a criterion. 

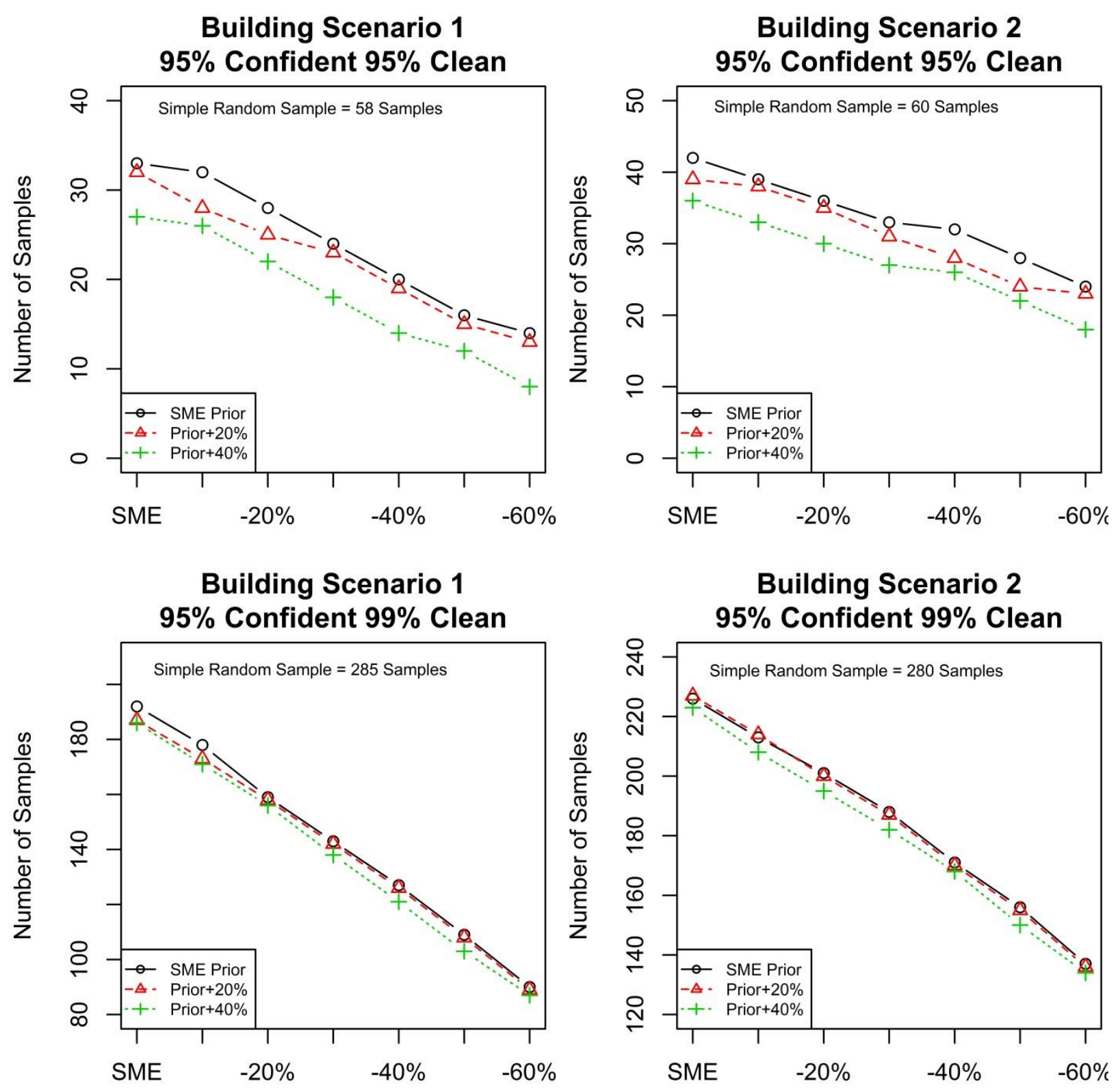

Figure 3.1 Sensitivity Analysis Results of the Numbers of Samples Needed for Each Scenario 


\subsection{Conclusions}

"Lines of evidence" is the ability to identify factors that are influencing the possible contamination of a given decision area and then convert this knowledge into probabilities estimating the likelihood of each area still being unacceptable. This paper shows how pre-determined identification of factors and elicitation from SME can be taken and then applied to a few different building scenarios. These estimates of probability can then be used with the stratified compliance sampling (SCS) approach to help reduce the number of samples necessary to determine clearance for the decision area. For this example set, sample sizes were reduced between $19 \%$ and $43 \%$ from the commonly used, simple random sampling approach.

This is just one example about how these probabilities can be determine and used with the SCS method. Other lines of evidence factors could be considered and other logistic regression models could be created to help build a model in which these probabilities could be calculated based upon any scenario. This would require SME expertise to identify the additional factors that influence contamination and SME expertise into the likelihood that an area would remain unacceptable given those factors. As was done in this example, statistical experimental design principles could be used to help in this process.

\subsection{References}

Ryan SP, Calfee MW, Wood JP, Attwood BC, Frank W. Schaeffer I. 2010. Research to Support the Decontamination of Surfaces and Buildings Contaminated wiht Biothreat Agents, p. 260-306. In William A. Rutala PD, M.P.H. (ed.), Disinfection, Sterilization, and Antisepsis. APIC, Washington, DC.

Dean, Angela and Daniel Voss. 1999. Design and Analysis of Experiments. Springer, New York.

Sego LH, KK Anderson, BD Matzke, WK Sieber, S Shulman, J Bennett, M Gillen, JE Wilson, and BA Pulsipher. 2007. An Environmental Sampling Model for Combining Judgment and Randomly Placed Samples. PNNL-16636, Pacific Northwest National Laboratory, Richland, Washington. Accessed March 8, 2012 at http://www.pnl.gov/main/publications/external/technical reports/PNNL-16636.pdf.

Sego LH, S Shulman, KK Anderson, JE Wilson, BA Pulsipher, and WK Sieber. 2010. Acceptance Sampling Using Judgmental and Randomly Selected Samples. PNNL-19315, Pacific Northwest National Laboratory, Richland, Washington. Accessed March 8, 2012 at

http://www.pnl.gov/main/publications/external/technical_reports/PNNL-19315.pdf.

U.S. Environmental Protection Agency (EPA). July 17-19, 2007. Guidance on test methods for demonstrating the efficacy of antimicrobial products for inactivating Bacillus anthracis spores on environmental surfaces. (http://www.epa.gov/scipoly/sap/meetings/2007/071707_mtg.htm)

U.S. Environmental Protection Agency (EPA). 2010. Determining the Efficacy of Liquids and Fumigants in Systematic Decontamination Studies for Bacillus anthracis Using Multiple Test Methods. Tech Report EPA/600/R-10/088.

Krauter PA, GF Piepel, R Boucher, M Tezak, BG Amidan, and W Einfeld. 2012. "False Negative Rate and Other Performance Measures of a Sponge-Wipe Surface Sampling Method for Low Contaminant Concentrations." Journal of Applied and Environmental Microbiology 78:846-854. 
Krose, DP, T Taimre, and ZI Botev. 2011. Handbook of Monte Carlo Methods. John Wiley and Sons, New York.

Matzke BD, JE Wilson, LL Nuffer, ST Dowson, JE Hathaway, NL Hassig, LH Sego, CJ Murray, BA Pulsipher, B Roberts, and S McKenna. 2010. Visual Sample Plan Version 6.0 User's Guide. PNNL-19915, Pacific Northwest National Laboratory, Richland, Washington. Available at: http://vsp.pnl.gov/docs/pnnl19915.pdf.

Piepel GF, BG Amidan, and R Hu. 2011a. Laboratory Studies on Surface Sampling of Bacillus anthracis Contamination: Summary, Gaps, and Recommendations. PNNL-20910, Pacific Northwest National Laboratory, Richland, Washington. Accessed March 8, 2012 at http://www.pnnl.gov/main/publications/external/technical_reports/PNNL-20910.pdf.

Piepel, G.F., B.G. Amidan, and R. Hu. 2012. "Laboratory Studies on Surface Sampling of Bacillus anthracis Contamination: Summary, Gaps, and Recommendations," Journal of Applied Microbiology, doi: 10.1111/j.1365-2672.2012.05381.x.

Rose LJ, L Hodges, H O'Connell, and J Noble-Wang. 2011. "National Validation Study of a Cellulose Sponge-Wipe Processing Method for Use after Sampling Bacillus anthracis Spores from Surfaces." Applied Environmental Microbiology 77:8355-8359. Accessed March 8, 2012 at http://aem.asm.org/content/77/23/8355.full.

Schilling EG and DV Neubauer. 2009. Acceptance Sampling in Quality Control, Second Edition. Chapman \& Hall/CRC Press, Boca Raton, Florida.

Sego LH and JE Wilson. 2007. Accounting for False Negatives in Hotspot Detection. PNNL-16812, Pacific Northwest National Laboratory, Richland, Washington. Accessed March 8, 2012 at http://www.pnl.gov/main/publications/external/technical reports/PNNL-16812.pdf.

Sego LH, KK Anderson, BD Matzke, WK Sieber, S Shulman, J Bennett, M Gillen, JE Wilson, and BA Pulsipher. 2007. An Environmental Sampling Model for Combining Judgment and Randomly Placed Samples. PNNL-16636, Pacific Northwest National Laboratory, Richland, Washington. Accessed March 8, 2012 at http://www.pnl.gov/main/publications/external/technical_reports/PNNL-16636.pdf.

Sego LH, S Shulman, KK Anderson, JE Wilson, BA Pulsipher, and WK Sieber. 2010. Acceptance Sampling Using Judgmental and Randomly Selected Samples. PNNL-19315, Pacific Northwest National Laboratory, Richland, Washington. Accessed March 8, 2012 at http://www.pnl.gov/main/publications/external/technical_reports/PNNL-19315.pdf.

Squeglia NL. 1994. Zero Acceptance Number Sampling Plans. ASQ Quality Press, Milwaukee, Wisconsin.

VSP Development Team. 2012. Visual Sample Plan: A Tool for Design and Analysis of Environmental Sampling, Version 6.0. Pacific Northwest National Laboratory, Richland, Washington. Available at http://vsp.pnnl.gov.

Wright T. 1992. "A Note on Sampling to Locate Rare Defectives with Strong Prior Evidence." Biometrika 79:685-691. 
Walton, GN \& WS Dols. 2013. CONTAM User Guide and Program Documentation. NISTIR 7251, U.S. Department of Commerce and National Institute of Standards and Technology. http://www.bfrl.nist.gov/IAQanalysis/docs/CONTAM_31.pdf.

Government Accountability Office (GAO). 2005. Anthrax detection: agencies need to 533 validate sampling activities in order to increase confidence in negative results (Report to 534 the Chairman, Subcommittee on National Security, Emerging Threats, and International 535 Relations, House Committee on Government Reform, House of Representatives), GAO-536 05-251, U.S. Government Accountability Office, Washington, DC. 



\section{Distribution}

No. of

Copies

\section{EXTERNAL DISTRIBUTION}

4 Department of Homeland Security

Don Bansleben (donald.bansleben@dhs.gov)

Randy Long (randolph.long@dhs.gov)

Segaran Pillai (segaran.pillai@dhs.gov)

Dana Saft (dana.saft@associates.hq.dhs.gov)

\section{Environmental Protection Agency}

Worth Calfee (calfee.worth@epa.gov)

Erica Canzler (canzler.erica@epa.gov)

Tonya Nichols (nichols.tonya @epa.gov)

Shawn Ryan (ryan.shawn@epa.gov)

Sanjiv Shah (shah.sanjiv@epa.gov)

1 The National Graduate School of Quality

Management

John Bridges (john.h.bridges@gmail.com)

\section{Federal Bureau of Investigation}

Doug Anders (douglas.anders@ic.fbi.gov)

Doug Beecher (douglas.beecher@ic.fbi.gov)

1 Department of Defense-ECBC

Vipin Rastogi (vipin.rastogi@us.army.mil)

2 Homeland Security Institute

Ed Hildebrand (carl.hildebrand@hsi.dhs.gov)

Eric Sylwester (eric.sylwester@hsi.dhs.gov)
No. of

Copies

7 Centers for Disease Control and Protection

Lisa Delaney (ldelaney1@cdc.gov)

Laura Rose (lmr8@cdc.gov)

Angela Weber (aweber@cdc.gov)

1 Sandia National Laboratories

Bob Knowlton (rgknowl@ sandia.gov)

\section{INTERNAL DISTRIBUTION}

13 Pacific Northwest National Laboratory

Brett Amidan (brett.amidan@pnnl.gov)

Rachel Bartholomew (rachel.bartholomew@pnnl.gov)

Cindy Bruckner-Lea (cindy.bruckner-lea@pnnl.gov)

Lisa Newburn (lisa.newburn@pnnl.gov)

Janine Hutchison (janine.hutchison@pnnl.gov)

Greg Piepel (greg.piepel@pnnl.gov)

Landon Sego (landon.sego@pnnl.gov)

Karen Wahl (karen.wahl@pnnl.gov)

Information Release 


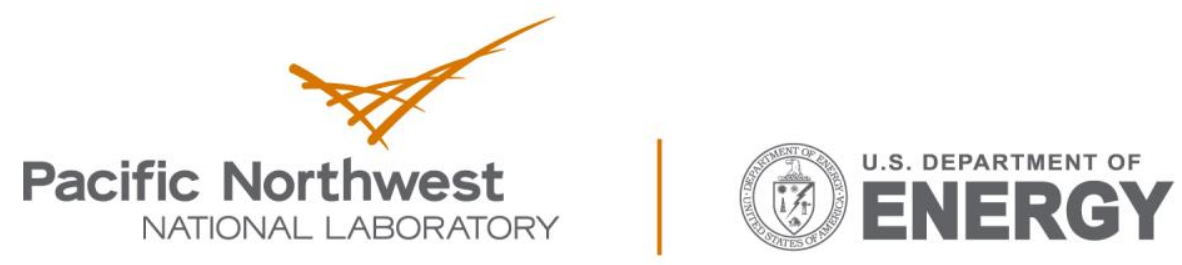

Proudly Operated by Battelle Since 1965

902 Battelle Boulevard

P.O. Box 999

Richland, WA 99352

1-888-375-PNNL (7665)

www.pnnl.gov 